The University of Maine

\title{
DigitalCommons@UMaine
}

Psychology Faculty Scholarship

Psychology

1985

\section{Assertiveness Training and Exposure In Vivo for Agoraphobics}

Geoffrey L. Thorpe

University of Maine - Main, geoffrey.thorpe@umit.maine.edu

Eric G. Freedman

University of Maine - Main

Joel D. Lazar

University of Maine - Main

Follow this and additional works at: https://digitalcommons.library.umaine.edu/psy_facpub

Part of the Psychology Commons

\section{Repository Citation}

Thorpe, Geoffrey L.; Freedman, Eric G.; and Lazar, Joel D., "Assertiveness Training and Exposure In Vivo for Agoraphobics" (1985). Psychology Faculty Scholarship. 19.

https://digitalcommons.library.umaine.edu/psy_facpub/19 


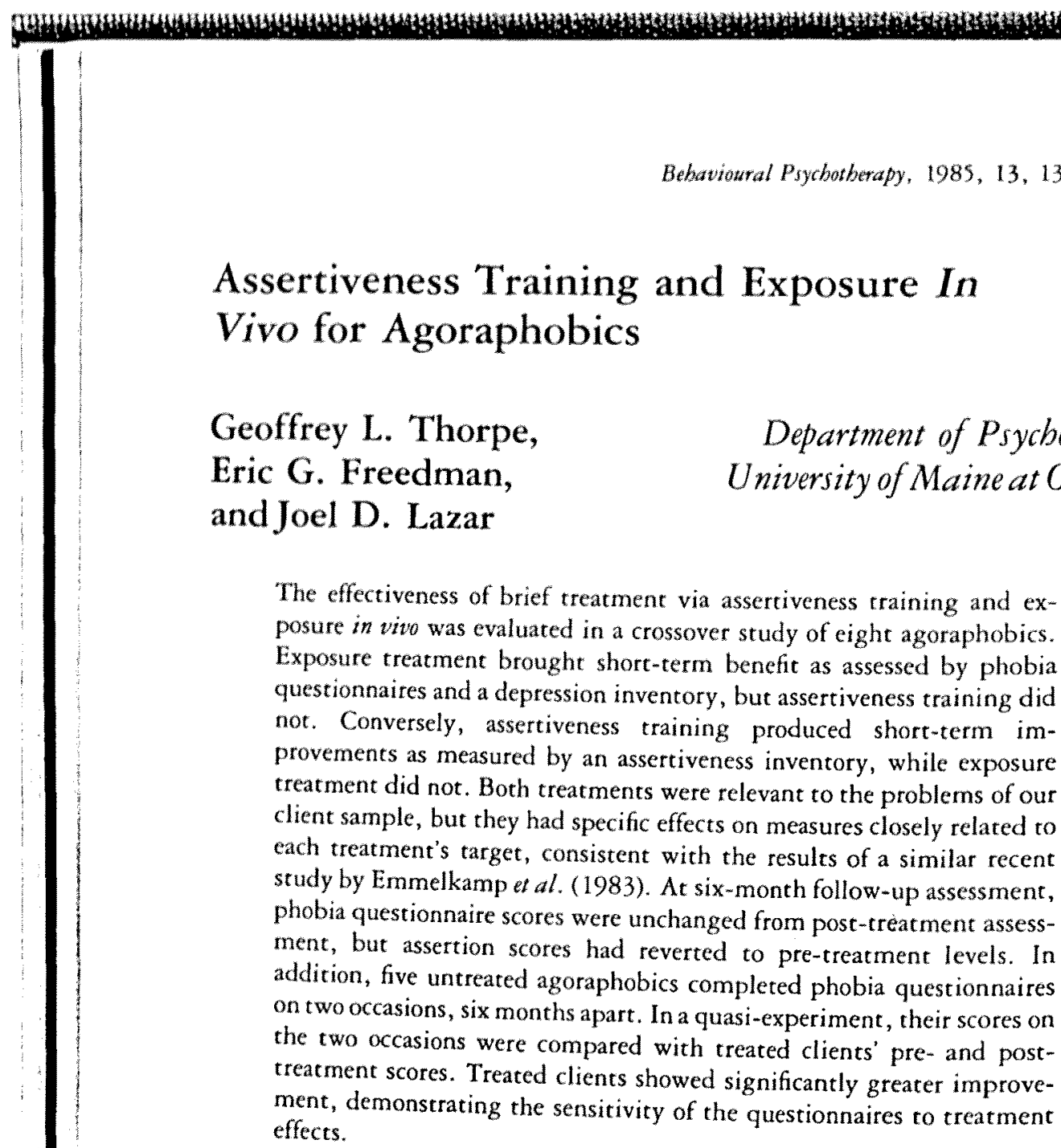

\title{
Assertiveness Training and Exposure In Vivo for Agoraphobics
}

\author{
Geoffrey L. Thorpe, \\ Eric G. Freedman, \\ and Joel D. Lazar
}

\author{
Department of Psychology
}

University of Maine at Orono

\begin{abstract}
The effectiveness of brief treatment via assertiveness training and exposure in vito was evaluated in a crossover study of eight agoraphobics. Exposure treatment brought short-term benefit as assessed by phobia Connaites and a depression inventory, but assertiveness training did an training produced short-term imby an assertiveness inventory, while exposure Both treatments were relevant to the problems of our study by Emmelkamp et al. (1983). At six-month follow-up assessment phobia questionnaire scores were unchanged from post-treatment assessment, but assertion scores had reverted to pre-treatment levels. In addition, five untreated agoraphobics completed phobia questionnaires on two occasions, six months apart. In a quasi-experiment, their scores on tho occasions were compared with treated clients' pre* and postment, demonstrating the sensitivity of the questionnaires to treatment effects.
\end{abstract}

\section{Introduction}

Agoraphobia is distressing, potentially disabling, and relatively prevalent, and researcher/clinicians have understandably paid much attention to it recently (Thorpe and Burns, 1983). As a result, effective treatments for the handicapping avoidance behavior of agoraphobics have been developed (Marks, 1981; Mathews et al., 1981). Yet many agoraphobics are described as having additional problems such as excessive dependency on others and low

\footnotetext{
A paper based on this research was presented at the 12 th Annual Conference of the British Association for Behavioural Psychotherapy, Nottingham, July 13, 1984

Requests for reprints, treatment manuals, or an extended report may be addressed to $G$. $L$. Maine 04469, U.S.A. Psychology, 301 Little Hall, University of Maine at Orono, Orono, 
self-sufficiency or assertiveness (Goldstein and Chambless, 1978; Thorpe et al., 1984), difficulties which may not be adequately addressed by procedures that successfully reduce fear and avoidance in specific phobic situations. Assertiveness training has been recommended as part of the treatment program for agoraphobics by Chambless and Goldstein (1980), and Emmelkamp and Mersch (1982) have called for research in this area, but despite the addition of assertiveness training procedures to behavior therapy regimens in some early studies (Gelder and Marks, 1966), no systematic information has been available until recently.

Emmelkamp et al. (1983) compared assertiveness training, exposure in vivo, and the combination of both treatments in a between-groups study of 21 unassertive agoraphobics. Ten three-hour group treatment sessions were given; there was a follow-up assessment one month after treatment. Exposure treatment was more effective than assertiveness training in producing change on phobia measures; the reverse was true for assertiveness measures. Both treatments made a contribution in helping unassertive agoraphobics.

We conducted an individual treatment program in which each client received assertiveness training and exposure in vivo in a crossover pattern. The study was designed and conducted before the results of Emmelkamp $t$ al. (1983) became available. Our hypotheses were that both treatments would bring short-term benefit on particular measures, and that on phobic treatment targets exposure treatment would prove superior to assertiveness training.

\section{Method}

Design

Clients applying for treatment of agoraphobia were invited to participate if (a) interview information confirmed the impression of agoraphobia and (b) they could attend the clinic for treatment. Each client had eight $1.5 \mathrm{~h}$ sessions of individual treatment, four devoted to assertiveness training and four to exposure in vivo. The order of the two treatment components was alternated for successive referrals. Therapists were four doctoral candidates in clinical psychology. Assessments were made before treatment, after the first four sessions, after all eight sessions, after any additional sessions, and six months after all treatment had ended.

\section{Clients}

Eight self-referred agoraphobics (six women, two men; mean age $=33$ years) began the treatment project in 1982. Level of assertiveness was not a criterion for inclusion. No agoraphobic who could attend the clinic was excluded. All eight expressed interest in both treatment components, but three clients 
stopped attending before the eighth session, leaving five who continued until at least the post-treatment assessment. Three of them had from four to eight extra treatment sessions and were remassessed afterwards; they were assessed finally after a six month interval of no treatment. Of the two remaining clients, one was re-assessed after six months, but the other had relocated and could not be traced.

In addition to these treated clients, six self-diagnosed agoraphobics who had contacted us for help, but who lived too far away to attend the clinic or for us to make home visits, agreed to complete phobia questionnaires sent by mail. All six were women (mean age $=37$ ). Six months later the questionnaires were sent again so that we could assess "fluctuations in agoraphobia over time". One person failed to return the second questionnaires.

\section{Assessment procedures}

Clients completed Burns' Agoraphobia Questionnaire, Section 39 (AQ 39; Thorpe and Burns, 1983, pp. 152-153); the Fear Questionnaire (FQ; Marks and Mathews, 1979), slightly modified in that fear and avoidance ratings were separated, as recommended by Wilson (1982); the Fear and General Symptom Questionnaire (FGSQ; Hallam and Hafner, 1978); and the Adult SelfExpression Scale (ASES; Gay et al., 1975), an assertiveness inventory. The untreated subjects completed the FQ and the AQ 39 only.

Ancillary measures used were the Beck Depression Inventory (BDI; Beck $t$ al., 1979, pp. 398-399) and the Maudsley Marital Questionnaire (MMQ; Crowe, 1978). Ratings of expectancy of benefit were made before each treatment.

For behavioral assessment, each client was asked to walk alone along a 2100-foot route through a University campus; distance walked and total time spent outside were recorded. Nine-point rating scales of fear, avoidance, and confidence were completed before and after each walk. Clients also gave confidence ratings after each treatment session on a form which listed nine landmarks along the behavioral assessment route; clients rated their degree of confidence about being able successfully to reach each point.

\section{Treatment procedures}

Detailed manuals of procedure were prepared (available from the authors). Therapists were trained in groups of two and supervised by the senior author. Assertiveness training sessions were audiotaped and recordings were discussed to ensure therapists' fidelity to the procedures. Clients were given a general rationale for the treatments in which the concept of emotional expressiveness 
in social relationships (assertiveness) was linked with tackling fear directly in phobic environments (exposure in vivo). Clients were encouraged to stop avoiding (a) embarrassment and fear in social situations by acting assertively, and (b) fear or panic in phobia-relevant situations by actively venturing into those surroundings at every opportunity.

Assertiveness training. Clients identified half a dozen problematic social interactions and rehearsed assertive responses by means of behavior rehearsal and cognitive restructuring methods. The emphasis of assertiveness training was on encouraging clients to express feelings openly, not necessarily to insist that the other person behave differently.

Exposture in vivo. Clients identified two or three challenging phobic situations (e.g. a large shopping center, a crowded campus cafeteria, a small elevator in the college library), entered each place with the support of the therapist, and remained there until fear declined appreciably. Clients were encouraged to go into the feared surroundings alone after the first two sessions, meeting the therapist in the office before and after each venture.

\section{Results}

For each measure, change from pre- to post-treatment (all eight sessions) was assessed by $t$-tests for correlated data. The effects of assertiveness training and exposure treatment were assessed separately in the same way, pooling the scores of the five clients before and after each treatment. One-tailed tests were made throughout.

Table 1 summarizes the questionnaire results. General improvement was noted on the $A Q 39$, the $\mathrm{BDI}$, and on most scales of the FQ. Exposure treatment produced significant improvement on the AQ 39, on Global Phobia and Anxiety/Depression scales of the FQ, and on the BDI, but assertiveness training did not. Assertiveness training brought benefit, where exposure treatment did not, on ASES scores. FGSQ scores were analyzed separately for the effects of assertiveness training and exposure; two-way analysis of variance with repeated measures (for the FGSQ subscales) showed that only exposure treatment produced significant change $(P<0.05)$, and on some scales more than others $(P<0.025)$. No changes were observed on the MMQ.

There was little variance on the behavioral test because all clients but one struggled hard, against instructions, to complete the walk pre-treatment. The rating scales completed after each walk were analyzed in the form of change scores from before to after each treatment. There was a significant interaction between treatment conditions and scales $(F(2,8)=5.38, P<0.05)$, 
TABLE 1. Summary of questionnaire data

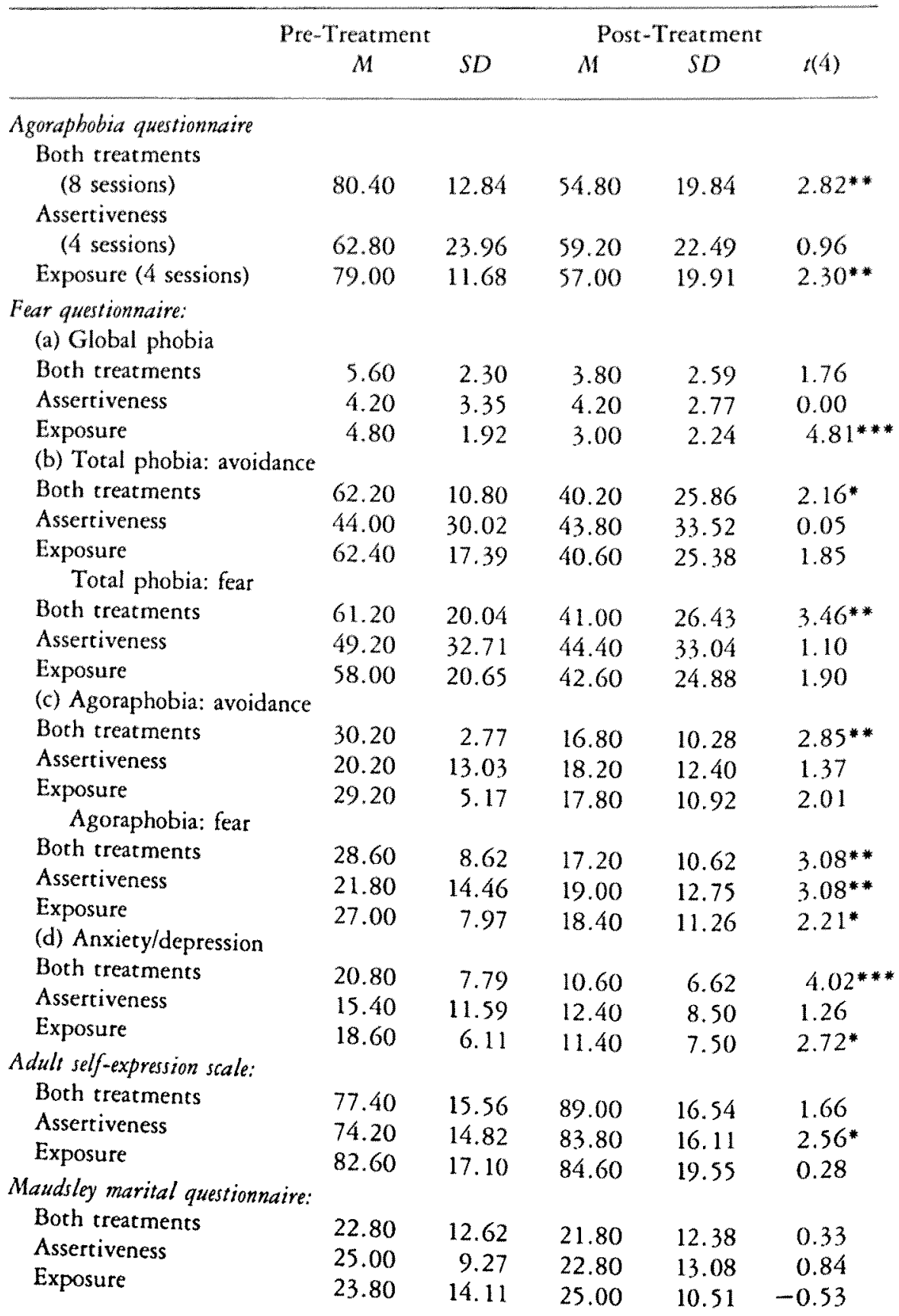


TABLE 1. cont.

\begin{tabular}{lccccc}
\hline & Pre-Treatment & \multicolumn{4}{c}{ Post-Treatment } \\
& $M$ & $S D$ & $M$ & $S D$ & $t(4)$ \\
\hline Beck Depression Intentory & & & & & \\
$\quad$ Both treatments & 11.00 & 7.38 & 7.40 & 6.58 & $2.71^{*}$ \\
Assertiveness & 9.20 & 9.09 & 9.40 & 9.34 & -0.20 \\
Exposure & 11.40 & 7.57 & 7.60 & 6.65 & $3.73^{* *}$ \\
\hline
\end{tabular}

$* P<0.05 ; * * P<0.025 ; * * * P<0.01$. All one-tailed.

indicating greater improvement on the anxiety rating in the exposure treatment condition.

No differences in ratings of expectancy of benefit were seen. The confidence ratings made after each treatment session did not show a treatmentcondition difference, but confidence increased as treatment progressed $(P<0.025)$.

\section{Six-month follou-up data}

Results for the four clients remaining for this assessment were evaluated by single-factor analysis of variance with repeated measures, using data from the initial assessment; the assessment following each client's last treatment session, including extra sessions; and the final assessment after a mean interval of seven months (range $=5$ to 10) of no treatment. On the AQ 39, post-treatment and follow-up scores were not significantly different from each 
other but both were significantly reduced (improved) from pre-treatment assessment $(P<0.01$, Newman-Keuls test). A similar pattern was seen for FQ Total Phobia scores, which were analyzed by two-way analysis of variance with repeated measures (see Figure 1). The ASES produced no significant findings on repeated measures analysis.

Comparison of treated and untreated clients

Questionnaire scores of the five untreated clients were tabulated for the first and second assessments (mean interval $=6$ months, range $=4$ to 7 months);

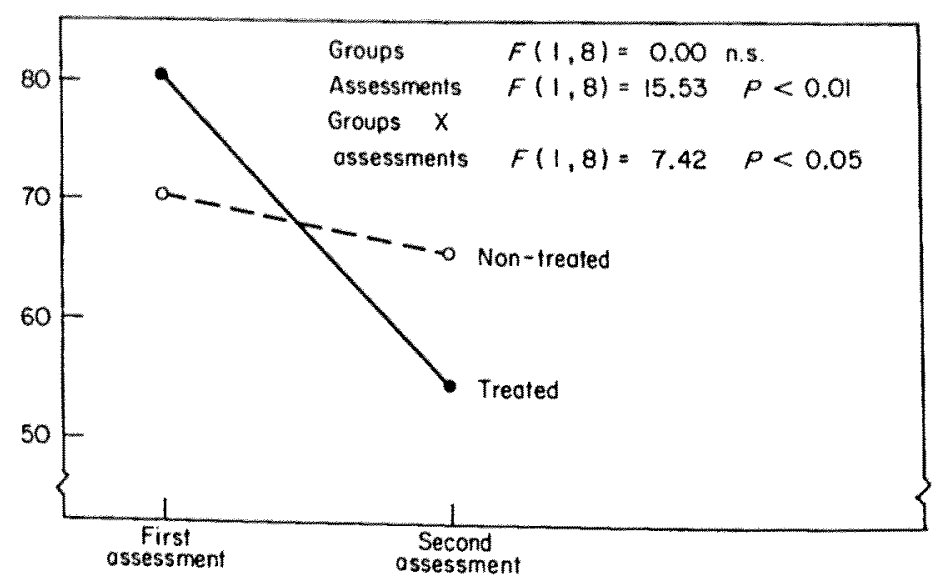

FIGURE 2. Agoraphobia questionnaire: group mean scotes for treated $(n=5)$ and nontreated $(n=5)$ clients. Reassessed after six months.

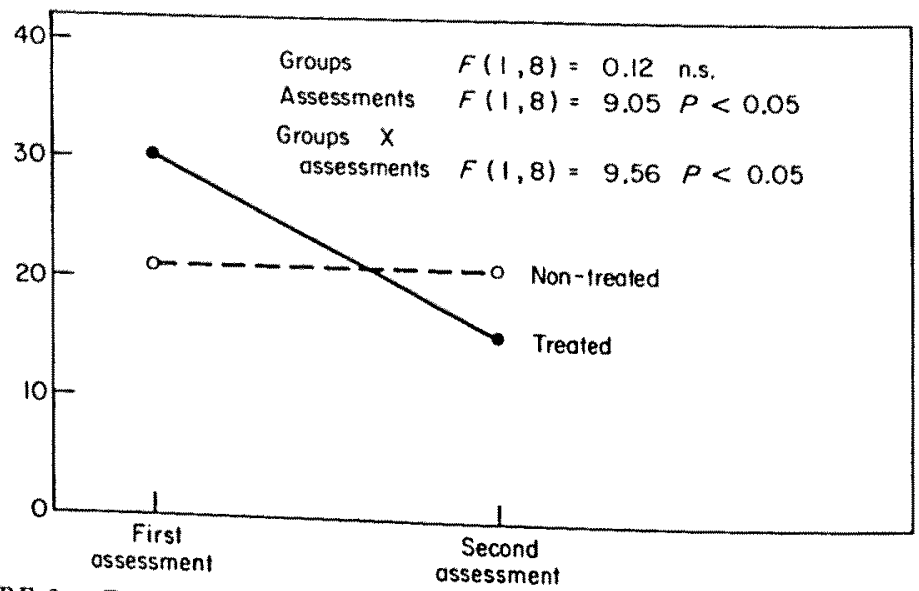

FIGURE 3. Fear questionnaire: agoraphobia. Group mean scores for treated $(n=5)$ and non-treated $(n=5)$ clients. Reassessed after six months. 


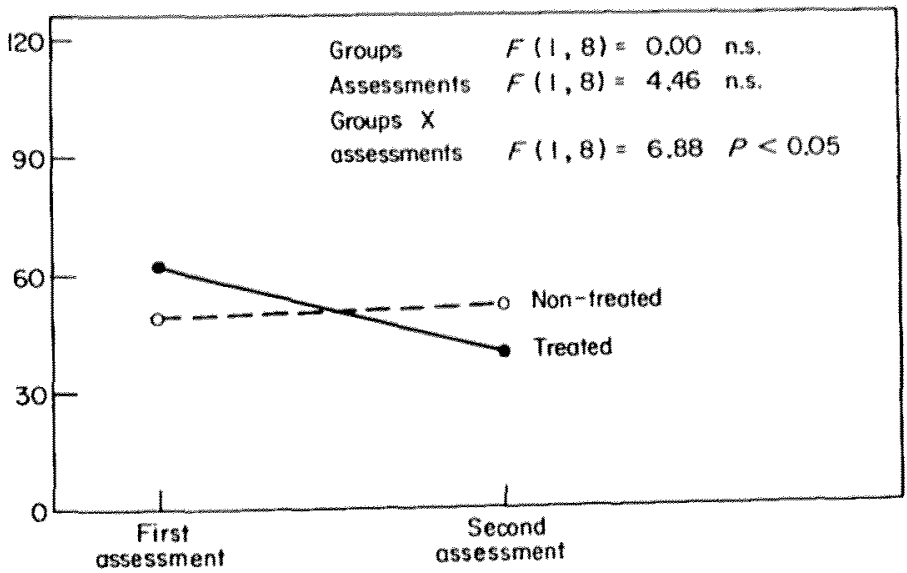

FIGURE 4. Fear questionnaire: total phobia. Group mean scores for treated $(n=5)$ and non-treated $(n=5)$ clients. Reassessed after six months.

scores of the five treated clients were tabulated for the pre-treatment assessment and the last assessment available before the final follow-up (mean interval $=6$ months, range $=4$ to 8 months). Groups showed no initial difference in questionnaire scores. In this quasi-experiment, treated clients showed greater change than untreated clients (see Figures 2, 3, and 4), illustrating the discriminant validity of both questionnaires in indicating treatment effects.

\section{Discussion}

A brief treatment program of eight sessions brought statistically significant changes on most measures (although we would not claim that our clients had entirely resolved their phobic problems). Exposure treatment produced improvements where assertiveness training did not on three different fear inventories, on the anxiety ratings after the unaccompanied walks, and on the depression inventory.

On the assertiveness inventory (ASES) only assertiveness training brought benefit, but this was short-lived, effects having eroded by the time of the six-month follow-up. Taken together with the observations that the three people who left treatment early did so during assertiveness training, and that two of the three clients who requested further treatment opted for exposure treatment, the results show that clients found exposure more helpful as treatment for agoraphobia.

Despite these findings, the therapists were impressed by the relevance of assertiveness training to each client, including the three who terminated early. To compare pre-treatment ASES means in our study and the Emmelkampet al. 
(1983) study: Our clients, who were not selected for unassertiveness, had a mean of 82.50 , very close to the 81.20 of the Emmelkamp et al. subjects, who had been selected for having assertiveness difficulties on this criterion. Our clients, then, were initially comparable to Emmelkamp's, who made greater improvernents in a longer treatment program. It is likely that our clients would have made further improvements in assertiveness with extended treatment.

Although assertiveness training procedures failed to reduce phobic fear and avoidance in these studies, assertiveness training could have an indirect and delayed effect: Clients could use the cognitive-behavioral techniques learned in assertiveness training to help them cope with phobic distress, or long-term changes in assertiveness could help modify a general pattern of passivity and avoidance. These possibilities could be evaluated in further research in which clients receive assertiveness training only, and are then re-assessed after a long follow-up interval to measure delayed effects on phobic behavior.

\section{Acknowledgements}

We are grateful to Norman Worgull and Mark Yaguda for their help in conducting this study.

\section{References}

Beck, A. T., Rush, A. J., Shaw, B. F. and Emery, G. (1979). Cognitive Therapy of Depression. New York: Guilford Press.

CHAmbless, D. L. and Goldstein, A. (1980). The treatment of agoraphobia. In The Handbook of Behavioral Interventions: A Clinical Guide. A. Goldstein and E. Foa (Eds.), New York: John Wiley, pp. 322-415.

Crowe, M. J. (1978). Conjoint marital therapy: A controlled outcome study. Psychological Medicine 8, 623-636.

EMMEL.KAMP, P. M. G. and MERSCH, P. P. (1982). Cognition and exposure in vivo in the trearment of agoraphobia: Short-term and delayed effects. Cognitive Therapy and Research 6, 77-90.

Emmelkamp, P. M. G., VAN der Hout, A. and De Vries, K. (1983). Assertive training for agoraphobics. Behaviour Research and Therapy 21, 63-68.

GAY, M. L., HollandsworTH, J. G. and Galassi, J. P. (1975). An assertiveness inventory for adults. Journal of Counseling Psychology 22, 340-344.

GeLder, M. G. and MARKs, I. M. (1966). Severe agoraphobia: A controlled prospective trial of behaviour therapy. British Journal of Psychiatry 112, 309-319.

Goldstein, A. J. and CHAmBless, D. L. (1978). A re-analysis of agoraphobia.
Behavior Therapy $9,47-59$. 
Hallam, R. S. and HafNer, R. J. (1978). Fears of phobic patients: Factor analyses of self-report data. Bebaviour Research and Tberapy 16, 1-6.

Marks, 1. (1981). Cure and Care of Neuroses: Theory and Practice of Behavioural Psychotberapy. New York: John Wiley.

MARKs, 1. M. and MATHEWS, A. M. (1979). Brief standard self-rating for phobic patients. Behaviour Research and Therapy 17, 263-267.

Matrews, A. M., Gelder, M. G., and Johnston, D. W. (1981). Agorapbobia: Nature and Treatment. New York: Guilford Press.

Thorpe, G, L., and Burns, L. E. (1983). The Agoraphobic Syndrome: Behavioural Approaches to Evaluation and Treatment. Chichester, UK: John Wiley.

Thorpe, G. L., Burns, L. E., Smith, P. J. and Blier, M J. (1984). Agoraphobia: Research developments and clinical implications. In New developments in behavior therapy: From research to dinical application, C. M. Franks (Ed.), New York: The Haworth Press, pp. 281-317.

WILSON, G. T. (1982). Fear reduction methods and the treatment of anxiety disorders. In Annual Review of Behavior therapy: Theory and Practice, Vol. 8, C. M. Franks, G. T. Wilson, P. G. Kendall and K. D. Brownell (Eds.), New York: Guilford Press.

(Date received: August 1984) 